\title{
Ban of Cosmetic Testing on Animals: A Brief Overview
}

\section{IJCRR}

Section: Healthcare

Sci. Journal Impact

Factor: 6.1 (2018)

ICV: 90.90 (2018)

\section{Sreedhar D. ${ }^{1}$, Manjula N. ${ }^{1}$, Ajay Pise ${ }^{2}$, Shilpa Pise ${ }^{2}$, Ligade VS ${ }^{1 *}$}

'Department of Pharmacy Management, Manipal College of Pharmaceutical Sciences,Manipal Academy of Higher Education, Manipal, Karnataka, India; ${ }^{2}$ Dadasaheb Balpande College of Pharmacy, Besa, Nagpur, Maharashtra, India.

Scopus

\section{ABSTRACT}

Introduction: Animals have been used in biomedical researchfor many years because they are considered as important experimental subjects due to their physiological similarity to human beings. Cosmetics are considered to be luxury products; they are not part of the essential commodity. Testing cosmetic ingredients on animals is primarily to check whether the product is safe for human use. Due to the increased concern for animals, to protect them from unnecessary pain and injuries many countries have passed,enacted Act made Rules and Regulations.

Objective: In the present study an attempt was made to explore various country statuses that have banned, in the progress of cosmetic testing on animals.

Methodology: The required information was obtained through secondary data sources, which were available onthe public domain.

Discussion: The first ban on animal testing of cosmetics products was started by the European Union.A full ban on both the sale and import of cosmetics that are tested on an animal was done in March 2013 by the European Union. India banned cosmetic testing on animals in 2014. New Zealand prohibited the use of animals for tests of cosmetic products since May 2015. Countries like Israel, Norway, Brazil, South Korea also banned cosmetic testing on animals.

Conclusion: This move from manycountries may protect cosmetic testing on animals from unnecessary pain and injuries.

Key Words: Biomedical Research, Animal Testing, Cosmetics Products.

\section{INTRODUCTION}

Animals have been used in biomedical research for many years. Usage of animals in a biomedical study is considered as important experimental subjects because of their physiological similarity to human beings. For establishing the safety and efficacy of drugs, experimentation on animals is usually unavoidable. Sometimes animals suffer injury, pain or suffering and even death. In India, Prevention of Cruelty to Animals Act, 1960, was introduced to prevent unnecessary pain or suffering from being inflicted on animals. ${ }^{1}$ As drugs are an essential commodity, for safety studies, animals are wildly used in preclinical studies for many serious diseases. Drugs, even cosmetic preparations are tested on animals for many years. Cosmetics are considered to be luxuryproducts; they are not part of the essential commodity. Testing cosmetic ingredients on animals is primarily to check whether the product is safe and hypoallergenic.
Cosmetic preparations contain many chemicals, so companies need to tests these chemicals for determination of toxicity, dosing and efficacy. To make cosmetic products safe to protect public health, it becomes mandatory for companies to perform these tests. Skin irritation, contact urticarial, stinging, allergic sensitization, phototoxicity and photoallergy are some of the adverse effects that may be caused due to cosmetic preparations. Various methods have been described to predict the potential of substances to induce irritation or sensitization. For detection of potential primary irritation, Draize test is performed where albino rabbits are clipped and the substance to be tested is applied. Some of the widely used tests for cosmetic products are testing of hair and bath preparations for eye irritation properties, test on eye mucosa of the albino rabbit. Repeated insult test for potential skin irritant through the skin, in case of unknown chemicals, some tests like provocative patch test are performed on animals like guinea pigs or rabbits. ${ }^{2}$

\section{Corresponding Author:}

Ligade VS, Department of Pharmacy Management, Manipal College of Pharmaceutical Sciences, Manipal Academy of Higher Education, Manipal, Karnataka, India; Email: virendra123sl@gmail.com

ISSN: $2231-2196$ (Print)

Received: 19.04 .2020
ISSN: $0975-5241$ (Online)

Revised: 02.06 .2020
Accepted: 21.06 .2020
Published: 22.07 .2020 
Over recent years,there is increased concern for animals, among animal welfare organizations, researchers, environmental activists, animal lovers and even among the common public. To protect animals from unnecessary pain and injuries many countries have passed legislation to ban the use of animals fortesting cosmetic products. The present study seeks to examinea few countries that have initiated, attempted to ban cosmetic testing on animals.

\section{The Scenario in Different Countries}

Due to growing concern over the use of animals on cosmetic testing, many countries have taken initiative, preparedplans to either completely ban or limit and regulate animal testing in respective countries. Few countries have implemented the ban process; in some countries, it is under progress.

Table 1: Scenario in different countries

\begin{tabular}{lc} 
Country & Banned year \\
Europe & $2013 / 2014$ \\
India & 2014 \\
Israel & 2013 \\
Taiwan & 2019 \\
Brazil (Sao Paulo) & 2014 \\
Guatemala & 2017 \\
\hline
\end{tabular}

\section{Europe}

EU was the first one to ban the testing of cosmetic products on animals. The very first ban on the selling of finished products was taken out in 2014, followed in 2008 by a ban on the use of products tested on animals. In March 2013 the European Union imposed a full ban on the sale and importation of cosmetics that were tested on animals or contain animal-tested ingredients. The EU is a wide marketplace for all cosmetics companies all over the world, and this policy has forced cosmetics companies to develop alternatives in places like China and SouthAmerica to find alternatives to animal testing methods. ${ }^{3,4}$

\section{India}

India banned cosmetic testing on animals in 2014. The new rule has been added to existing Drugs and Cosmetic Rules, 1945 by Ministry of health and family welfare. As per new rule, it is prohibited to test cosmetics on animals and no person shall use any animal for testing cosmetic preparations. India has now also implemented a ban on importing such products that test on animals. ${ }^{5,6}$

\section{Israel}

Israel prohibited the production, sale and promotion of cosmetics, toiletries and household cleaners that were tested on animals. Personal-care and household products were banned within the country in 2007 . The government introduced a new law in 2010, which entered into force on 1 January 2013, regarding the banning of imported products that have been tested on animals in other countries. ${ }^{7,8}$

\section{Brazil}

In January 2014 Sao Paulo becomes the first of four states in Brazil to ban cosmetic animal testing for products and ingredients. In September 2015 Brazilian policymaker proposes amendments to cosmetics bill to incorporate a ban on animal-tested ingredients and the sale of newly animal-tested cosmetics. ${ }^{9}$

\section{Taiwan}

Taiwan has introduced legislation banning the testing of cosmetic products on animals. The bill is supposed to come into force in 2019. The ban will not, however, include the selling of imported cosmetics. ${ }^{10,11}$ This projected bill has now been passed taking Taiwan into line with about 30 countries which have now banned cosmetic animal testing. The ban will not, however, affect the selling of imported products.

\section{Guatemala}

In 2017, Guatemala banned cosmetic animal testing. ${ }^{12}$

\section{Turkey}

Testing of cosmetic ingredients or formulations on animals was banned by Turkey's cosmetics Regulation, where there is a validated alternative method. Turkey's Pharmaceuticals and Medical Devices Administration enforced the ban via an enacted amending regulation, published in the Official $G a$ zette. It says products manufactured using animal testing are no longer allowed to enter the country's market if the testing happened after a relevant alternative method had been validated at EU or OECD level. The amendment further bans the placing on the market of finished products that have been tested on animals. ${ }^{13}$

\section{South Korea}

In 2018 the Korea National Assembly also decided to ban the production of cosmetics tested on animals. It comes 2 years ago than originally planned.The Ministry of Agriculture, Food and Rural Affairs of South Korea has announced plans to ban cosmetic animal testing. Testing finished products on animals will be prohibited under the government's Five Year Plan for Animal Welfare, and further debate will go into a ban on testing ingredients. ${ }^{14}$

\section{New Zealand}

Under the Animal Welfare Act 1999, New Zealand prohib- 
ited the use of animals in developing, making, or testing an ingredient that is intended exclusively for use in a cosmetic. ${ }^{15,16}$

\section{Norway}

Selling cosmetics tested on animals within the EU-including Norway-is prohibited. Strict rules have been in place over the past decade to control when and how animal testing is being used in cosmetics production. The EU has further tightened the rules and prohibited all imports and sales of cosmetics tested on animals in Europe. ${ }^{18}$

\section{Russia}

A bill that proposes a ban on animal testing for cosmetics and cosmetics ingredients in the place of alternatives is currently under scrutiny by Russia's parliament. The bill seeks a phase-out of testing on animals and ingredients tested on animals but only in the presence of suitable alternatives. The partial bill targets to enforce a ban on domestic analysis by 1 January 2020, and marketing by 1 January 2022. However, there were concerned over the cost implications of imposing the ban. ${ }^{18}$

\section{Australia}

Australia prohibits the use of animals for safety testing in cosmetics. The ban also includes the selling of cosmetics and products which have been tested on animals outside the Australia. ${ }^{19}$

\section{China}

China has initiated towards cruelty-free cosmetics. China had policy meant animals used in cruel tests for imported cosmetics in January 2017. New regulations were issued which will potentially mean some cosmetic will not now be subject to this requirement. ${ }^{20}$

Alternative methods for animal testing are still at the nascent stage. Validation and legal acceptance of methods alternative testing are in progress. There is more research needed as no alternative methods that could fully assess all toxicological endpoints. ${ }^{21}$

\section{CONCLUSION}

Over recent years, there is increased concern for animals used in experimentsamong all spectrum of society. To protect experimental animals from unnecessary pain and injuries there is the need of the hour especially in the case of cosmetic products. The good headwayis being made on animal testing by some countries. EU was the pioneer in setting the benchmark for the same. India banned animal testing on cosmetic in 2014, first in Asia was the welcome move. Many countries are trying to bring new regulations, amendments related to use of animals in cosmetic preparation. This move will protect the animals from unnecessary suffering all over the world.

Acknowledgement: Authors acknowledge the immense help received from the scholars whose articles are cited and included in references of this manuscript. The authors are also grateful to authors / editors / publishers of all those articles, journals and books from where the literature for this article has been reviewed and discussed.

\section{Conflict of interest: None}

\section{Financial support: None}

\section{REFERENCES}

1. Jain NK. Editor. A Textbook of Forensic Pharmacy. Delhi: Vallabh Prakashan;2014.

2. Sharma PP. Editor. Cosmetics- Formulation, Manufacturing and Quality control. Delhi: Vandana Publications; 2014.

3. Report: These Countries Have Banned Cosmetics Animal Testing. Cited from URL: https://www.skincarewatchdog.com/ report-these-countries-have-banned-cosmetics-animal-testing/ [Accessed on February 15, 2020]

4. EU extends ban on animal-tested cosmetics. Cited from URL: https://www.euronews.com/2013/03/11/eu-extends-ban-on-animal-tested-cosmetics. [Accessed on February 15, 2020]

5. Govt. bans cosmetic companies from testing on animals. The Times of India.Cited from URL:https://timesofindia.indiatimes. com/city/mumbai/Govt-bans-cosmetic-companies-from-testing-on-animals/articleshow/29225017.cms[Accessed on February 25,2020$]$

6. India bans import of cosmetics tested on animals. The Times of India. Cited from URL:https://timesofindia.indiatimes.com/ india/India-bans-import-of-cosmetics-tested-on-animals/articleshow/44814398.cms[Accessed on February 25, 2020]

7. Kretzer M. Cited from URL: https://www.peta.org/blog/israelbans-animal-tested-products/[Accessed on March 1, 2020]

8. Import ban on animal-tested products goes into effect. The Times of Israel. Cited from URL:https://www.timesofisrael. com/import-ban-on-animal-tested-products-goes-into-effect/ [Accessed on March5,2020]

9. São Paulo Bans Animal Testing". AFP News. Cited from URL: https://www.petmd.com/news/care-safety/sao-paulo-bans-animal-testing-31269[Accessed on March 6,2020]

10. Taiwan bans animal testing. Cited from URL:https://www.cosmeticsbusiness.com/news/article_page/Taiwan_bans_animal testing/122305.[Accessed on March 10,2020]

11. Taiwan bans cosmetics animal testing. Humane Society International. Cited from URL: https://www.hsi.org/news-media/ taiwan-bans-cosmetics-animal-testing-072116/.[Accessed on March 15, 2020]

12. Guatemalan Congress approves animal testing ban. Cruelty Free International. Cited from URL: www.crueltyfreeinternational. org. [Accessed on March 15, 2020]

13. Turkey restricts animal testing of cosmetics. Cited from URL: https://chemicalwatch.com/30839/turkey-restricts-animal-testing-of-cosmetics[Accessed on March 15, 2020]

14. Korea announces ban on animal testing for cosmetics. Cited from URL: https://www.crueltyfreeinternational.org/breaking- 
news/korea-announces-ban-animal-testing-cosmetics/[Accessed on March 25,2020]

15. Animal Welfare Act 1999. Cited from URL: http://www.legislation.govt.nz/act/public/1999/0142/latest/DLM6475801.html. [Accessed on March 25, 2020]

16. MPs unanimously support animal testing ban". Radio New Zealand. Cited from URL: https://www.rnz.co.nz/news/political/270097/mps-unanimously-support-animal-testing-ban.[ Accessed on March 16, 2020]

17. Ban on animal testing of cosmetics. Cited from URL: http:// www.norwaypost.no/index.php/culture/museums/28252 [Accessed on March 24,2020]

18. Russia questions cost of animal testing ban for cosmetics.Cited from URL: https://www.cosmeticsbusiness.com/news/article_
page/Russia_questions_cost_of_animal_testing_ban_for_cosmetics/116886. [Accessed on January 5, 2020].

19. Ban on the use of animal test data for cosmetics. Cited from URL: https://www1.health.gov.au/internet/main/publishing.nsf/ Content/ban-cosmetic-testing-animals. [Accessed on April 5, 2020]

20. Animal testing in the cosmetics industry. Cited from URL: https://www.ethicalconsumer.org/health-beauty/animal-testingcosmetics-industry [Accessed on April 27, 2020]

21. Grum T. Global ban on animal testing: where are we in 2019? Cited from URL: https://www.cosmeticsdesign-europe.com/Article/2019/03/05/Global-ban-on-animal-testing-where-are-wein 2019?utm_source=copyright\&utm_medium=OnSite\&utm campaign $=$ copyrightAccessed on [April 27,2020] 